\title{
Subterranean Pitfall Traps: Is It Worth Including Them in Your Ant Sampling Protocol?
}

\author{
Renata Pacheco and Heraldo L. Vasconcelos \\ Instituto de Biologia, Universidade Federal de Uberlândia (UFU), C.P. 593, 38400-902 Uberlândia, MG, Brazil \\ Correspondence should be addressed to Heraldo L. Vasconcelos, heraldo@umuarama.ufu.br
}

Received 17 May 2011; Accepted 28 June 2011

Academic Editor: Jonathan D. Majer

Copyright ( 2012 R. Pacheco and H. L. Vasconcelos. This is an open access article distributed under the Creative Commons Attribution License, which permits unrestricted use, distribution, and reproduction in any medium, provided the original work is properly cited.

\begin{abstract}
The use of subterranean traps is a relatively novel method to sample ants, and few studies have evaluated its performance relative to other methods. We collected ants in forests, savannas, and crops in central Brazil using subterranean pitfall traps and conventional pitfall traps placed on the soil surface. Sampling duration, soil depth, and sprinkling vegetal oil around traps all tended to affect the number of species found in subterranean traps. Sixteen percent of the species collected in subterranean traps were unique, and most of these had cryptobiotic morphology (i.e., were truly hypogaeic species). Surprisingly, however, subterranean and conventional traps were similarly efficient at capturing cryptobiotic species. Furthermore, subterranean traps captured far fewer species in total than conventional traps (75 versus 220 species), and this was true in all three habitats sampled. Sampling completeness increased very little using a combination of conventional and subterranean traps than using just conventional traps.
\end{abstract}

\section{Introduction}

Biodiversity inventories seek a characterization of the studied community or the elaboration of a complete species list [1]. In both cases a more efficient inventory is commonly achieved with the use of diverse and complementary sampling techniques, and this is especially true with regard to hyperdiverse groups such as terrestrial arthropods [1-3]. Ants are a particularly important group of arthropods as they are highly abundant and diverse, have a wide geographic distribution, and occupy a variety of niches [4]. Ants play important ecological roles, acting as herbivores, seed dispersers or, commonly, as predators and scavengers of other arthropods $[4,5]$. Due to these characteristics, ants have been commonly used as a focal taxon in biodiversity studies or as bioindicators in studies of land management [6].

Diverse methodologies have been used to collect ants, and each of them has its own limitations given that no single method is able to collect all species inhabiting a given area (at least not in tropical and subtropical habitats where ant diversity is typically high), since these species commonly have a wide diversity of foraging and nesting habits $[1,7-9]$.
As a result, many ant inventories employ more than one sampling technique, as their use in combination often increases sampling efficiency $[1,9,10]$. Pitfall traps, for instance, tend to be more efficient for the collection of relatively large ants that are active on the soil surface, whereas the Winkler method favors the collection of smaller and often cryptic species that forage or nest in the litter layer [11]. The combined use of pitfall traps and the Winkler samples has been proposed in the Ants of Leaf Litter (ALL) sampling protocol, a protocol that has been employed successfully in ecological studies and inventories of tropical forest ants $[7,12,13]$. More recent studies, however, have indicated that many species with subterranean habits (i.e., hypogaeic species with cryptobiotic morphology) may not be collected with the use of the more traditional sampling methodologies such as the Winkler method, pitfall traps, baits, or direct search $[12,14,15]$. One way to collect hypogaeic species is to take soil-core samples and extract ants from soil manually or with the aid of the Berlese or the Winkler extractors $[10,16-18]$. An alternative and increasingly used method is subterranean traps, such as the subterranean probe $[15,19]$ or subterranean pitfall traps [14,20-23]. 
So far, inventories of ant diversity using subterranean traps have been performed in only a small number of sites and habitats including the rain forests of Ecuadorian Amazon [19], the Brazilian Atlantic Forest [22], and the Eucalyptus-dominated forests of northern Australia [14]. Therefore, there is a lack of information about the performance of subterranean traps in other types of vegetation. Also, there is only limited information about the best methods to improve the sampling efficiency of subterranean traps (but see [14]). Here we provide results of the first systematic survey of subterranean ants in the Cerrado region of central Brazil. The Cerrado is a biodiversity hotspot and is characterized as a mosaic of vegetation types, which include savannas of variable structure (the dominant vegetation), various types of forests, and grasslands [24, 25]. Most of the original Cerrado vegetation have already been converted to cattle pastures or crop fields, and as a consequence these human-managed ecosystems are now an important feature of the Cerrado landscape and thus have also to be taken into account when assessing diversity at the landscape level.

Pitfall trapping (i.e., pitfall traps placed on the soil surface or, hereafter, conventional pitfalls) is by far the most commonly employed method to sample ants, especially in savanna-dominated landscapes $[9,13,26]$. We thus compared the efficiency of subterranean traps relative to conventional pitfall traps and, most importantly, determined how complementary these two methodologies are. Trap efficiency was measured in terms of the total number of species collected, the number of unique species, and the number of species with cryptobiotic morphology (i.e., species with tiny or absent eyes and small body size). We also evaluated some simple methodologies designed to improve the sampling efficiency of subterranean traps. Finally, we evaluated the efficiency of subterranean traps in collecting hypogaeic ants in different types of ecosystems of the Cerrado region, including forests, savannas, and crop fields.

\section{Material and Methods}

2.1. Study Site. The study was conducted in 13 sampling sites located near the towns of Uberlândia $\left(18^{\circ} 56^{\prime}, 48^{\circ} 18^{\prime} \mathrm{W}\right)$ and Monte Alegre de Minas $\left(18^{\circ} 52^{\prime} \mathrm{S}, 48^{\circ} 52^{\prime} \mathrm{W}\right)$ in the west region of Minas Gerais state in Brazil. The region is characterized by a tropical climate with two well-defined seasons: a dry winter (May-September) and a rainy summer (OctoberApril). The mean annual temperature and precipitation are $22^{\circ} \mathrm{C}$ and $1650 \mathrm{~mm}$, respectively. Sampling was conducted during the wet seasons of 2008 and 2009.

Soils at our study sites are primarily red latosols. The vegetation at these sites included savannas (locally known as cerrado sensu stricto; $n=2$ sites), forests (semideciduous forests and the forest physiognomy locally known as cerradão [25]; $n=5$ sites), and fields planted with annual crops (maize, sorghum or, most commonly, soybean) $(n=6)$. With a single exception, all sites with natural vegetation were adjacent to the crop fields.

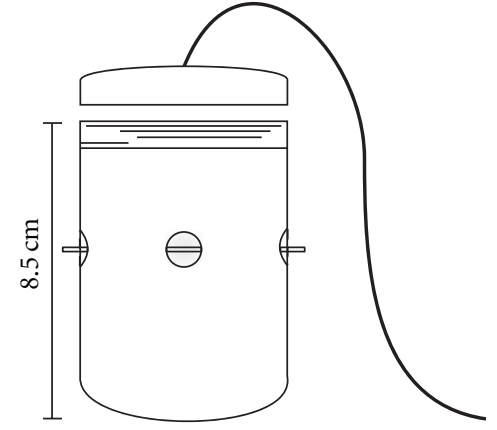

(a)

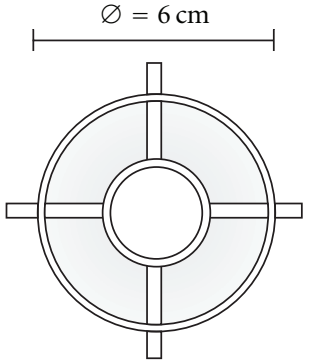

(b)
Figure 1: Schematic external (a) and internal (b) view of the subterranean pitfall trap.

2.2. Description of the Subterranean Trap. Our subterranean pitfall traps (Figure 1) were similar to those employed by other authors $[14,21,22]$. Each trap consisted of a closed plastic container (volume $=250 \mathrm{~mL}$ ) with four $1 \mathrm{~cm}$ holes made in the side of the container (Figure 1). As done in a previous study [22], a $70 \mathrm{~cm}$ long rope was attached to the lid of each container to identify its location and facilitate removal. The traps were baited using sardine mixed with vegetable oil. About $5 \mathrm{~mL}$ of this mixture was poured onto a small lid $(2.5 \mathrm{~cm}$ in diameter $)$, and the lid was fixed in the interior of each container suspended by a plastic frame as detailed in Figure 1. About $50 \mathrm{~mL}$ of alcohol and glycerin was poured on the bottom of the traps to act as killing and preservative agents.

2.3. Factors Affecting Trap Efficiency. To evaluate if the number of species collected varied with soil depth, we simultaneously buried 60 traps to a depth of $20 \mathrm{~cm}$ and 60 traps to a depth of $50 \mathrm{~cm}$. To prevent major alterations on soil structure, we buried traps by first making a cylindrical hole (ca. $8 \mathrm{~cm}$ in diameter) using a post hole digger [22] and then filled the holes with the excavated soil. These traps remained in operation for 7 days and were placed along transects in three sites (one forest, one savanna, and one crop field site), keeping a minimum distance of $20 \mathrm{~m}$ between traps and alternating the treatments (i.e., 20 or $50 \mathrm{~cm}$ ). Twenty traps of each type were installed in each site.

We also evaluated if trapping duration affected the number of species collected. For this we compared the number of species collected in 40 of the 60 traps set at $20 \mathrm{~cm}$ for the experiment described above with the number of species collected in 40 other traps that were buried to a depth of $20 \mathrm{~cm}$ and were left out in the field for just two days. Traps that were left in the field for two days were installed in the same sites and at the same time as those that were left for 7 days. Finally, we evaluated if pouring vegetable oil around the hole made to bury each trap would increase the number of species collected as indicated in previous studies in Malaysia [20, 27, 28]. For this we sprinkled about $20 \mathrm{~mL}$ of a mixture consisting of $90 \%$ of soybean oil and $10 \%$ of palm (Elaeais guineensis, known as dendê in Brazil) oil on 
TABLE 1: Efficiency of the subterranean pitfall traps as a function of soil depth, time of trap exposure, and addition of vegetable oil on soil around traps.

\begin{tabular}{lcccccccc}
\hline Factor & Treatment & $\begin{array}{c}\text { Number of } \\
\text { traps (natural } \\
\text { areas + crops) }\end{array}$ & $\begin{array}{c}\text { Observed } \\
\text { number of } \\
\text { species (SD) }\end{array}$ & $\begin{array}{c}\text { Estimated } \\
\text { number of } \\
\text { species (SD) }\end{array}$ & $\begin{array}{c}\text { Observed } \\
\text { number of } \\
\text { cryptobiotic } \\
\text { species (SD) }\end{array}$ & $\begin{array}{c}\text { Estimated } \\
\text { number of } \\
\text { cryptobiotic } \\
\text { species (SD) }\end{array}$ & $\begin{array}{c}\text { Total number } \\
\text { of ant species } \\
\text { records }\end{array}$ & $\begin{array}{c}\text { Traps } \\
\text { without ants } \\
(\%)\end{array}$ \\
\hline \multirow{2}{*}{ Duration } & 2 days & $20+20$ & $13( \pm 3.1)$ & $21.8( \pm 3.0)$ & $2( \pm 0.0)$ & $3.0( \pm 1.0)$ & 27 & 50.0 \\
\multirow{2}{*}{ Depth } & 7 days & $20+20$ & $17( \pm 2.1)$ & $24.8( \pm 2.5)$ & $5( \pm 1.6)$ & $8.9( \pm 1.9)$ & 37 & 40.0 \\
\multirow{2}{*}{ Vegetable oil } & $20 \mathrm{~cm}$ & $40+20$ & $20( \pm 2.6)$ & $29.8( \pm 2.9)$ & $6( \pm 1.7)$ & $10.9( \pm 2.1)$ & 43 & 53.3 \\
& $50 \mathrm{~cm}$ & $40+20$ & $16( \pm 3.3)$ & $27.8( \pm 3.4)$ & $3( \pm 1.9)$ & $4.0( \pm 1.0)$ & 27 & 63.3 \\
\hline
\end{tabular}

the soil around each trap. A total of 60 traps received this treatment while another 60 did not. These traps were buried to a depth of $20 \mathrm{~cm}$ and remained in operation for 7 days (20 of the 60 traps that received no oil treatment were the same traps used in the experiment about soil depth). As in the previous experiments, traps were spaced $20 \mathrm{~m}$ from each other (alternating treatments), with 40 of the traps from each treatment being placed in two forest sites and 20 in a crop field (Table 1).

\subsection{Subterranean Traps versus Traps Placed on the Soil Surface.} To determine if more species would be collected using a combination of conventional, and subterranean traps than using just conventional traps we installed these two types of traps in our sampling sites $(n=13)$. In addition to traps used in the previous experiments, we installed another 505 subterranean traps and 605 conventional traps in our sampling sites. Within each of these sites, traps were distributed along line transects, keeping a minimum distance of $20 \mathrm{~m}$ between traps and alternating the type of trap. Subterranean and conventional traps were installed simultaneously in each transect. Conventional pitfall traps consisted of plastic cups ( $300 \mathrm{~mL}$ volume), filled to one third of its volume with a mixture of alcohol (70\%) and glycerin and placed on the ground so that the opening of the trap was leveled off with the soil surface.

All the additional 505 subterranean traps were set at $20 \mathrm{~cm}$ of depth (and vegetable oil was poured around the traps as described above) and remained in operation for 7 days. The conventional traps also remained in operation for 7 days, and both types of traps were baited using sardine mixed with vegetable oil.

2.5. Data Analysis. We built sample-based species accumulation curves [29], using the Mao Tau estimator in EstimateS version 8.2 [30], in order to compare the overall number of species collected and the number of cryptobiotic species collected at different depths, after different times of trap exposure, after applying or not vegetable oil around traps, and for comparing subterranean and conventional traps. We used the Jackknife 1 nonparametric richness estimator to determine the number of species expected to be found in different types of traps (or treatments) or in different habitats.
Nonmetric multidimensional scaling (NMDS) was used to evaluate the similarity in ant species composition among samples taken in different habitats or using different sampling methodologies. For this we first constructed a dissimilarity matrix (Sørensen index) using data on species presence or absence for species collected with each of the two sampling methodologies in each sampling site. The resulting ordination scores (two-dimensional solution) were then used in a multivariate analysis of variance (Manova) to test for differences in ant species composition (expressed as ordination scores) in relation to habitat and sampling method.

Of the 260 subterranean traps installed for the first three experiments, 22 were lost to digging animals (most of which in the crop fields) and, therefore, were excluded from our analyses. Of the 505 subterranean traps used in the subsequent experiment (when we protected the traps with a wire mesh fixed on the soil surface), only 6 were lost. Of the 605 conventional traps, 33 were lost and excluded from the analyses.

\section{Results}

3.1. Improving the Sampling Efficiency of Subterranean Pitfall Traps. The median number of species collected per trap was not significantly affected by soil depth (Mann-Whitney test, $\left.U_{60,60}=2058, P=0.19\right)$, time of trap exposure $\left(U_{40,40}=\right.$ $675, P=0.12)$, or the addition of vegetable oil on soil around traps $\left(U_{48,50}=1340, P=0.20\right)$. Similar results were obtained when data was analyzed considering only the species with cryptobiotic morphology (Mann-Whitney test, $P>0.05$ in all cases). Nevertheless, when we compared the cumulative number of species collected (i.e., in all traps from each treatment), there was a clear trend towards finding more ant species, more species records, and less traps with no ants in traps that remained 7 days in operation, in those that were set at $20 \mathrm{~cm}$ of depth, and in those around which vegetable oil was poured (Table 1). Traps that remained in the field for 7 days also captured more cryptobiotic species in total than those that remained for two days. Similarly, more cryptobiotic species were found at 20 than at $50 \mathrm{~cm}$ of depth. The cumulative number of cryptobiotic species collected in traps with the addition of vegetable oil was equal to the number collected in traps with no oil (Table 1). 
3.2. Subterranean Traps versus Traps Placed on the Soil Surface. We collected a total of 75 ant species from 27 genera in the 737 subterranean traps placed in 13 different sites and in three habitats (Table 2). Of all species collected with subterranean traps, 15 were cryptobiotic ( $20 \%$ of the total). Twelve of the 75 species (16\%) captured with the subterranean traps were not found in the conventional traps, and most of these ( 8 out of 12 species) were cryptobiotic.

Using only the conventional traps ( $n=572$ traps), we collected a total of 220 species from 49 genera (a complete list of species/morphospecies is available from the authors upon request). Most of these species (157 species, or $71.3 \%$ of the total) were not found in the subterranean traps. Sixteen of the species collected using conventional traps (7.3\%) were cryptobiotic (Table 2), and half of these were not captured with the subterranean traps.

The total number of species collected in the conventional traps was much greater than the number collected using subterranean traps, and this difference was detected in all three habitats sampled (forests: 4.3 more species, savannas: 3.7 more species, crop fields: 2.5 more species in the conventional than in the subterranean traps) (Figuers 2(a)$2(\mathrm{c}))$. When comparing the total number of species collected using just the conventional traps with that collected using both conventional and subterranean traps, we found that the number collected with the latter was only slightly greater than with the former (5.4\% greater overall, $4.1 \%$ greater in forests, $5.8 \%$ greater in savannas, and $4.9 \%$ greater in crop fields). Considering only the species with cryptobiotic morphology, we found that conventional traps captured more species in the forest sites (Figure 2(d)), whereas in the crop fields subterranean traps tended to be more efficient (Figure 2(f)). Subterranean and conventional traps captured similar number of cryptobiotic species at the savanna sites (Figure 2(e)).

Overall (i.e., considering the two trapping methods), the proportion of species with cryptobiotic morphology varied a little among habitats, ranging from $9 \%$ of all species collected in forests to $8.4 \%$ in crops (savannas $=8.7 \%$ ) (Table 3 ). The number of cryptobiotic species collected in each habitat represented 64 to $73 \%$ of the number of cryptobiotic species expected to be found in these same habitats (Table 3 ).

Most of the species collected only in the subterranean traps were rare species that were found in only one or two traps (Table 2). These included, for instance, two species of Acanthostichus, three species of Hypoponera, one species of Carebara (lignata group), Oxyepoecus inquilinus, and the exotic Tetramorium simillimum (Table 2). On the other hand, some of the species often collected with subterranean traps were not collected or were rare in the conventional traps. For instance, Neivamyrmex punctaticeps was collected 18 times with the subterranean traps but never with the conventional traps, while Labidus mars was collected 17 times with the subterranean traps but only once (and only a single individual) with the conventional traps (Table 2). As a result, differences in species composition resulting from collections using different types of traps tended to be even greater than differences in species composition between different habitats sampled with the same type of trap (Figure 3), even though differences in both habitat type (Manova, Pillai trace $=0.783$, $\left.F_{4,40}=6.43, P<0.001\right)$ and trap type were significant (Manova, Pillai trace $=0.821, F_{2,19}=43.66, P<0.001$ ).

\section{Discussion}

4.1. Increasing Trap Efficiency. Although during the past few years there has been a substantial increase in the use of subterranean traps in ant surveys [14, 15, 19-22], few studies have evaluated how to improve the efficiency of these traps. Our results suggest that extending the time of trap exposure from two to seven days increases trap efficiency in terms of total number of ant species records, total number of ant species, and number of cryptobiotic species. Similarly, Andersen and Brault [14] report that total ant records in subterranean traps were about $40 \%$ greater after four days than after just one. However, in their study, the number of species recorded did not change as a result of sampling duration (24 species after four as well as after one day) [14]. Although the number of additional ant species collected in subterranean traps appears to decline strongly as a function of sampling duration (with nearly $80 \%$ of the species being collected during the first $24 \mathrm{~h}$ of sampling) [19], we recommend that traps should remain in the field for more than two days and ideally for four to seven days. This is because installing the traps is a relatively time-consuming and labor intensive operation, and once the traps are set, few are lost (provided that some protection against digging animals is made). Therefore, unless there is the need to move to another and relatively distant sampling site quickly, there is no point in removing the traps after just one or two days.

Our results also suggest that sprinkling vegetal oil around the traps increases trap efficiency at least in terms of the overall number of species collected. Sprinkling vegetal oil on soil has been found to attract several hypogaeic ant species in Malaysia, especially army ants $[20,27,28]$. In the studies in Malaysia the oil used to attract ants was palm oil, while here we used a mix of palm (dendê) and soybean oil, given the elevated price of palm oil in Brazil. Palm oil has a very strong odor, and this odor is not lost after mixing it with soybean oil. Although vegetable oil has been found to increase trap efficiency, future studies should evaluate the use of other types of ant baits (in combination with oil), since vegetable oil is not attractive to all hypogaeic species [20].

As also found in other studies [14, 19], ant species tended to decline with soil depth. Furthermore, no evidence of a vertical stratification of the ant fauna was detected, as basically the same species were collected in different depths (Table 2). Wilkie et al. [19] suggested that in contrast to the situation they found in Ecuador, where the water table is particularly high, studies in dryer landscapes could detect a relatively unique deep-soil ( $>25 \mathrm{~cm}$ in depth) fauna. Our results suggest that this is may not be the case, as even though the water table at our sites is very deep, we found the same species foraging at different depths.

None of the previous studies that used subterranean traps provide data on the proportion of traps with no ant records. Our data indicate that, at least in our study region, this figure can be elevated and that $40 \%$ or more of the traps capture no 
TABLE 2: List of all ant species collected with subterranean pitfall traps and list of all cryptobiotic species (marked with an asterisk) found during the study. Shown is the number of records (i.e., number of traps in which the species was present) of each species in different habitats, soil depths, and in total. The total number of records for each species in the conventional traps is also provided.

\begin{tabular}{|c|c|c|c|c|c|c|c|}
\hline \multirow{2}{*}{ Species } & \multicolumn{3}{|c|}{ Habitat } & \multicolumn{2}{|c|}{ Depth } & \multirow[t]{2}{*}{ Total subterranean } & \multirow[t]{2}{*}{ Total conventional } \\
\hline & Forest & Savanna & Crops & $20 \mathrm{~cm}$ & $50 \mathrm{~cm}$ & & \\
\hline Acanthostichus kirbyi* & & 1 & & 1 & & 1 & \\
\hline Acanthostichus sp. nr. brevicornis* & & 1 & & 1 & & 1 & \\
\hline Acromyrmex sp.6 & 1 & & & 1 & & 1 & 1 \\
\hline Acromyrmex subterraneus molestans & & & 1 & 1 & & 1 & 73 \\
\hline Acromyrmex subterraneus subterraneus & 1 & & & 1 & & 1 & 41 \\
\hline Atta laevigata & 1 & & & 1 & & 1 & 135 \\
\hline Brachymyrmex sp. 2 & & & 1 & 1 & & 1 & 100 \\
\hline Camponotus sp.10 & & & 1 & 1 & & 1 & 26 \\
\hline Camponotus sp.40 & 1 & 1 & & 2 & & 2 & 43 \\
\hline Carebara brevipilosa* & 3 & & 1 & 4 & & 4 & 26 \\
\hline Carebara sp.1 (lignata gp.)* & & 1 & & 1 & & 1 & \\
\hline Carebara sp.2 (lignata gp.)* & 1 & & & & & & 1 \\
\hline Carebara urichi* & & & 1 & 1 & & 1 & 5 \\
\hline Cephalotes pusillus & 2 & & & 2 & & 2 & 22 \\
\hline Crematogaster rudis & & 3 & 1 & 3 & 1 & 4 & 28 \\
\hline Dorymyrmex brunneus & & 1 & 13 & 14 & & 14 & 196 \\
\hline Dorymyrmex sp.6 & & & 2 & 2 & & 2 & 39 \\
\hline Dorymyrmex goeldii & & & 3 & 3 & & 3 & 60 \\
\hline Ectatomma sp. 5 & 1 & & 1 & 2 & & 2 & 102 \\
\hline Ectatomma brunneum & & 1 & 6 & 6 & 1 & 7 & 96 \\
\hline Ectatomma opaciventri & & & 2 & 2 & & 2 & 117 \\
\hline Ectatomma planidens & & 2 & & 1 & 1 & 2 & 34 \\
\hline Gnamptogenys sp. 1 & & & 1 & 1 & & 1 & 15 \\
\hline Gnamptogenys haenschi & 4 & & & 4 & & 4 & 1 \\
\hline Hypoponera sp.2 & 1 & & & & 1 & 1 & 1 \\
\hline Hypoponera sp.5 & 1 & & & 1 & & 1 & \\
\hline Hypoponera sp.6 & 1 & & & 1 & & 1 & \\
\hline Hypoponera sp. $8^{*}$ & 1 & & & & & & 1 \\
\hline Hypoponera sp.11* & & & 1 & & & & 1 \\
\hline Hypoponera sp.1 (punctatissima gp.)* & & & 1 & 1 & & 1 & \\
\hline Hypoponera sp.3 (punctatissima gp.)* & 1 & & & & & & 1 \\
\hline Hypoponera cf. trigona* & 4 & & & & & & 4 \\
\hline Labidus coecus* & 1 & 1 & 4 & 6 & & 6 & 23 \\
\hline Labidus mars* & 3 & 7 & 7 & 15 & 2 & 17 & 1 \\
\hline Labidus praedator* & 1 & & & 1 & & 1 & 7 \\
\hline Mycocepurus goeldii & & 1 & & 1 & & 1 & 122 \\
\hline Mycocepurus cf. smithii & & 1 & & 1 & & 1 & 14 \\
\hline Myrmicocrypta sp.3 & 1 & & & 1 & & 1 & \\
\hline Neivamyrmex bruchi* & 7 & 21 & 4 & 27 & 5 & 32 & 7 \\
\hline Neivamyrmex modestus* & 3 & & & & & & 3 \\
\hline Neivamyrmex cf. pseudops* & & 2 & & & & & 2 \\
\hline Neivamyrmex punctaticeps* & 17 & & 1 & 17 & 1 & 18 & \\
\hline Octostruma jheringi* & & 1 & & 1 & & 1 & 1 \\
\hline Oxyepoecus inquilinus & & & 1 & 1 & & 1 & \\
\hline Pachycondyla guianensis* & 1 & & & 1 & & 1 & \\
\hline Pachycondyla obscuricornis & & 1 & & & 1 & 1 & 76 \\
\hline
\end{tabular}


TABle 2: Continued.

\begin{tabular}{|c|c|c|c|c|c|c|c|}
\hline \multirow{2}{*}{ Species } & \multicolumn{3}{|c|}{ Habitat } & \multicolumn{2}{|c|}{ Depth } & \multirow[t]{2}{*}{ Total subterranean } & \multirow[t]{2}{*}{ Total conventional } \\
\hline & Forest & Savanna & Crops & $20 \mathrm{~cm}$ & $50 \mathrm{~cm}$ & & \\
\hline Pheidole sp.1 & 1 & 6 & 28 & 34 & 1 & 35 & 203 \\
\hline Pheidole sp.2 & 2 & 4 & 2 & 7 & 1 & 8 & 76 \\
\hline Pheidole sp.3 & & 3 & 7 & 8 & 2 & 10 & 38 \\
\hline Pheidole sp.A & & 1 & & 1 & & 1 & 2 \\
\hline Pheidole sp.4 & 1 & 3 & 8 & 11 & 1 & 12 & 36 \\
\hline Pheidole sp.5 & & & 2 & 1 & 1 & 2 & 8 \\
\hline Pheidole cf. fowleri & 9 & 10 & 12 & 31 & & 31 & 174 \\
\hline Pheidole sp.C (diligens gp.) & & 1 & & 1 & & 1 & 19 \\
\hline Pheidole sp.10 & & & 1 & 1 & & 1 & 16 \\
\hline Pheidole sp.D & 2 & & & 2 & & 2 & 24 \\
\hline Pheidole sp.12 & & 1 & 3 & 3 & 1 & 4 & 93 \\
\hline Pheidole sp.13 & 1 & & & 1 & & 1 & 21 \\
\hline Pheidole sp.16 & & 4 & 5 & 9 & & 9 & 28 \\
\hline Pheidole sp.17 & & 1 & 6 & 7 & & 7 & 28 \\
\hline Pheidole sp.18 & & & 1 & 1 & & 1 & 48 \\
\hline Pheidole sp.20 & 4 & 3 & 6 & 13 & & 13 & 4 \\
\hline Pheidole sp.21 & & & 1 & 1 & & 1 & 17 \\
\hline Pheidole sp.24 & 2 & & & 2 & & 2 & 6 \\
\hline Pheidole sp. 25 & 2 & & & 2 & & 2 & 28 \\
\hline Pheidole sp.33 & 1 & & & 1 & & 1 & 1 \\
\hline Pheidole sp.36* & 2 & & & 2 & & 2 & \\
\hline Pheidole sp.38 & 1 & & & 1 & & 1 & 21 \\
\hline Pheidole sp.54 & & & 1 & 1 & & 1 & 4 \\
\hline Pheidole fimbriata & 33 & & & 33 & & 33 & 27 \\
\hline Pheidole oxyops & 8 & 1 & 32 & 41 & & 41 & 281 \\
\hline Pogonomyrmex naegelli & & & 2 & 2 & & 2 & 90 \\
\hline Prionopelta cf. antillana* & & & 1 & 1 & & 1 & 14 \\
\hline Sericomyrmex sp.1 & 1 & & & 1 & & 1 & 15 \\
\hline Sericomyrmex sp.2 & 2 & & & 2 & & 2 & 23 \\
\hline Solenopsis sp.1 & 3 & 1 & 1 & 4 & 1 & 5 & 101 \\
\hline Solenopsis sp.2 & & 1 & 1 & 2 & & 2 & 25 \\
\hline Solenopsis iheringi & 3 & & & 3 & & 3 & 50 \\
\hline Solenopsis saevissima & 2 & 5 & 48 & 49 & 6 & 55 & 97 \\
\hline Tetramorium simillimum & & 1 & & 1 & & 1 & \\
\hline Trachymyrmex sp.7 & 1 & & & 1 & & 1 & 3 \\
\hline Typhlomyrmex sp.1* & 2 & & & & & & 2 \\
\hline Wasmannia auropunctata & 2 & 2 & 1 & 5 & & 5 & 32 \\
\hline
\end{tabular}

ants. This indicates that subterranean ants are relatively rare, with low density in the soil. In this sense, we may still need to develop methods to improve trap efficiency. Potential ways to improve trap efficiency include putting various types of baits on the soil around traps (as discussed above), making a large number of perforations in the traps (to facilitate ant access), and/or replacing baits periodically as done in some studies $[19,20]$.
4.2. Subterranean Traps versus Traps Placed on the Soil Surface. Sixteen percent of the species that we collected with subterranean traps were not collected with conventional pitfalls. Similarly, in Ecuador, $19.1 \%$ of the species collected with subterranean probes were not collected with other methods $[15,19]$, while the use of subterranean traps in Northern Australia resulted in the collection of $13.8 \%$ of unique species in one site and of $47 \%$ in another [14]. 


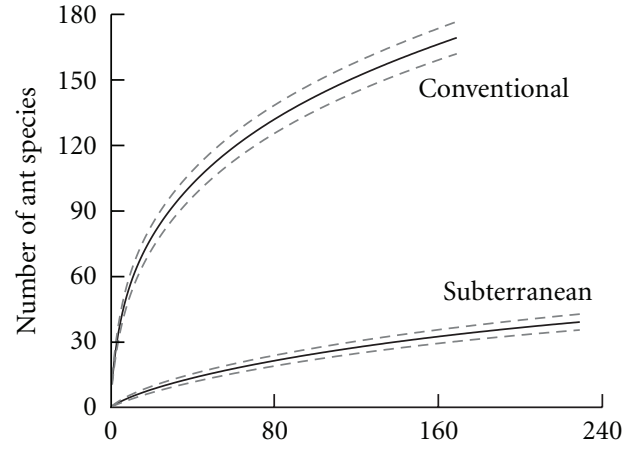

(a)

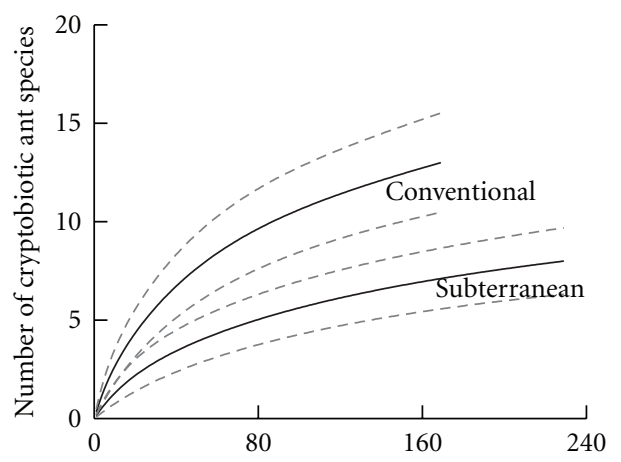

(d)

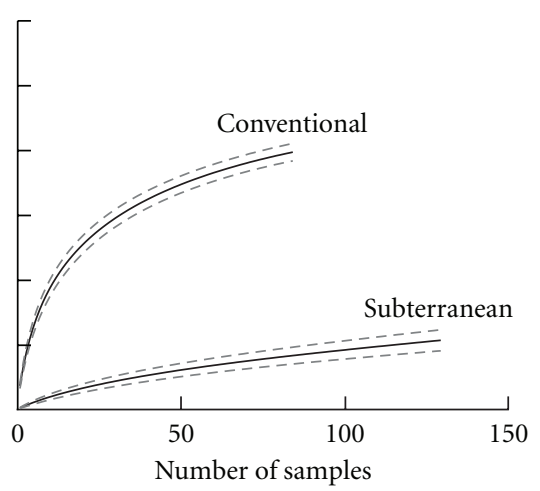

(b)

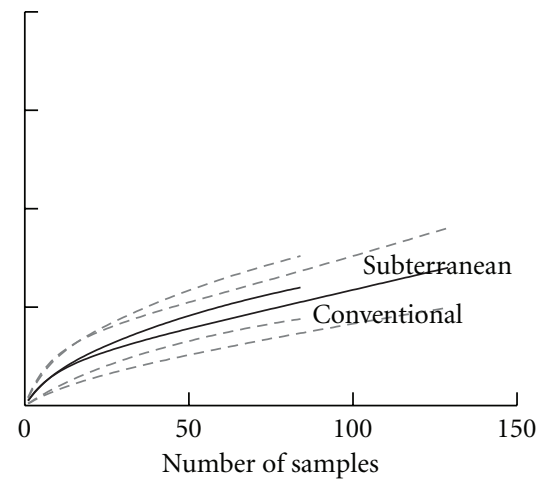

(e)

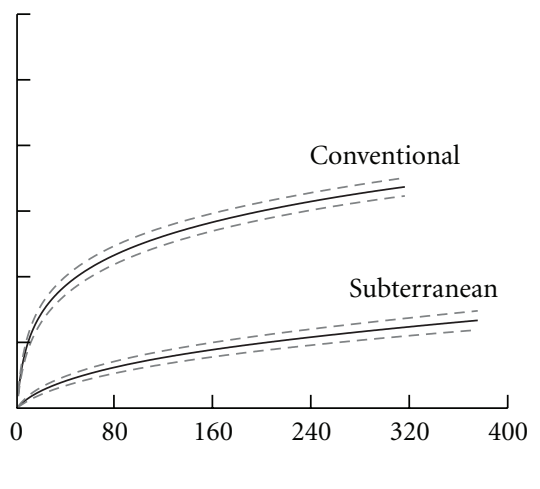

(c)

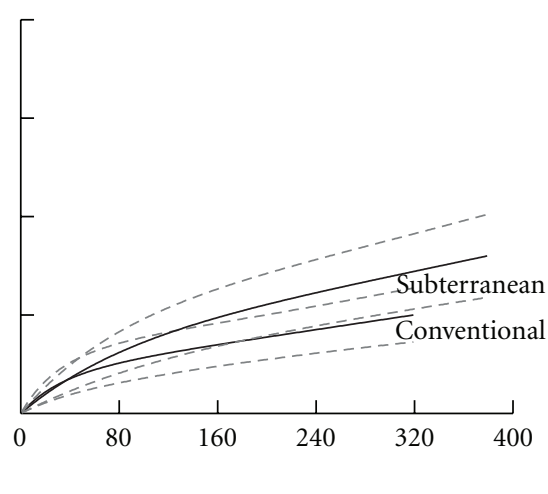

(f)

FIGURE 2: Sample-based species accumulation curves of the total number of ant species and the number of cryptobiotic species collected in subterranean or in conventional (i.e., on soil surface) pitfall traps placed in forests (a, d), savannas (b, e), or crop fields (c, f). Dotted lines represent one standard deviation around mean values.

TABLE 3: Overall ant species richness and richness of cryptobiotic species in three different habitats. Shown is the observed and estimated $( \pm \mathrm{SD})$ number of species (Jacknife 1 species richness estimator).

\begin{tabular}{lcccc}
\hline & \multicolumn{2}{c}{ All species } & \multicolumn{2}{c}{ Cryptobiotic species } \\
\hline $\begin{array}{l}\text { Habitat } \\
\text { (no. of traps) }\end{array}$ & $\begin{array}{c}\text { Observed } \\
\text { species } \\
\text { richness }\end{array}$ & Estimated & $\begin{array}{c}\text { Observed } \\
\text { species } \\
\text { richness }\end{array}$ & Estimated \\
\hline Forest (398) & 177 & $190.9 \pm 6.1$ & 16 & $21.0 \pm 2.2$ \\
Savanna (213) & 126 & $156.9 \pm 6.0$ & 11 & $15.0 \pm 2.2$ \\
Crops (698) & 107 & $133.0 \pm 5.6$ & 9 & $13.0 \pm 2.0$ \\
Total (1309) & 232 & $291.0 \pm 7.9$ & 23 & $32.0 \pm 3.0$ \\
\hline
\end{tabular}

${ }^{*}$ Including subterranean and conventional traps.

Most of the species unique to our subterranean traps had cryptobiotic morphology (i.e., were truly hypogaeic species). However, surprisingly, subterranean traps were not more efficient than conventional traps in collecting cryptobiotic species. In fact, in the forest sites more cryptobiotic species were captured using conventional than subterranean traps (Figure 2). In addition, most of the cryptobiotic species found in the two types of traps (such as Carebara brevipilosa,
Carebara urichi, Labidus coecus, Labidus praedator, and Prionopelta cf. antillana; Table 2) were more frequent in the conventional than in the subterranean traps. The only species that we can confidently say that are really more likely to be collected in our sites using subterranean than conventional pitfall traps are the army ants Labidus mars and Neivamyrmex punctaticeps. Nevertheless, it may well be possible that these two species could perhaps be more easily detected if we had used other methods designed specifically for finding army ants [23].

Overall (i.e., considering all species), subterranean traps collected far fewer species than conventional traps (see also [15] for a comparison between subterranean traps and other more traditional methods), indicating that ant diversity is much greater above- than below-ground. We collected two to four times more (depending on the type of habitat) species using conventional pitfall traps than using subterranean traps. Furthermore, when considering the overall number of species collected using both conventional and subterranean traps (232 species), only 5.2\% were not collected using the conventional traps. In other words, the number of species collected by using a combination of subterranean and conventional traps was only slightly greater than the number those collected using just the conventional traps. This raises the question: is it worthwhile to include subterranean pitfall 


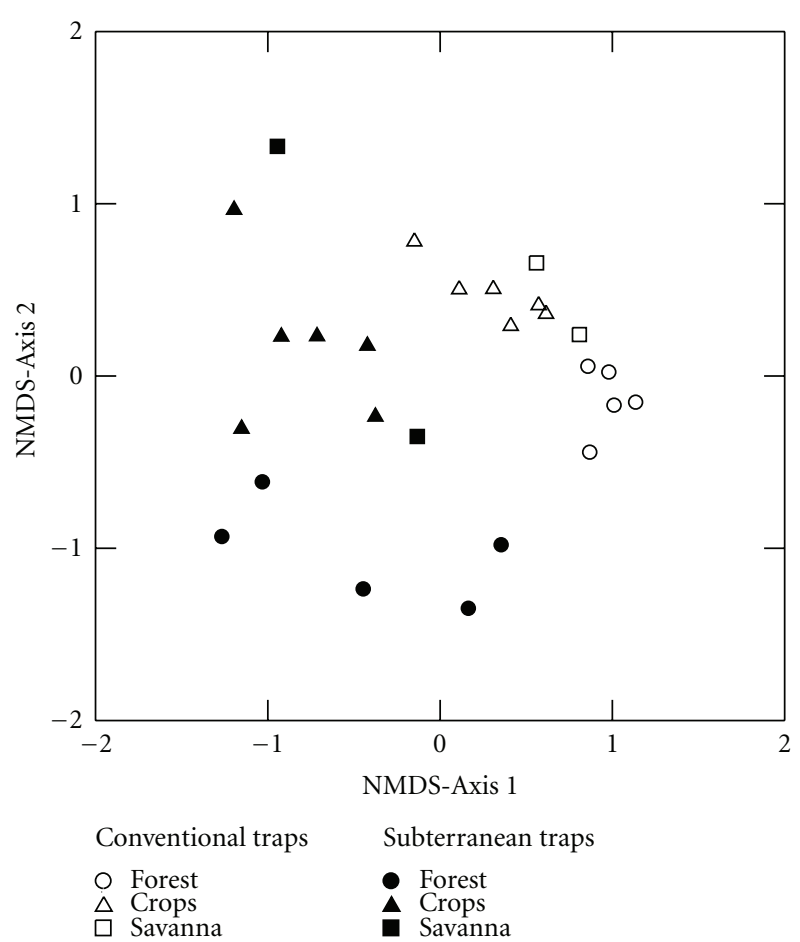

FIgURE 3: Nonmetric multidimensional scaling (NMDS) ordination of transects placed in different habitats based on the composition of ant species captured in subterranean or in conventional pitfall traps.

traps in your ant sampling protocol? In our view, if the purpose of the sampling is to provide just a general characterization of the studied ant communities, then the response is no. This is because many more species will be collected by using, say, 100 conventional pitfall traps than by using 50 conventional and 50 subterranean traps. In this way, even though a few cryptobiotic species would be missed (or their abundances underestimated), the completeness of the sampling would be much greater. Similarly, subterranean traps would probably not add much more information when the goal of the study is to compare the ant fauna of different habitats, since our results indicate that in most habitats conventional traps are at least as efficient as subterranean traps in collecting cryptobiotic species and, in addition, they collect much more species overall. On the other hand, if the purpose of the sampling is to evaluate the degree of vertical stratification of the ant fauna [31] or, especially, provide a relatively accurate species list (or a more reliable description of the functional composition of the studied community), then the response is yes. This is because some species are less likely to be recorded unless some kind of method to sample hypogaeic ants is employed. Examples include the first record of Neivamyrmex punctaticeps and Labidus mars in the Cerrado (this study), the rediscovery of Simopelta minina in the Atlantic forest $[22,32]$, the record of a new genus (Pseudolasius) for Western Australia [14], and the discovery of new species [19] and even new ant subfamilies [18, 33] by sampling subterranean ants. In this sense, we agree with previous claims that the subterranean ant fauna represents a novel and important frontier in biodiversity inventories $[14,19]$. But to better explore this frontier we still need studies that compare the efficiency of the different methods developed so far, including traps, probes [15, 19], sieved buckets [20], and soil-core sampling [10, 16-18], taking into account the costs of each method and their efficiency in terms of the number and uniqueness of the species collected.

\section{Acknowledgments}

The authors are grateful to Gabriela P. Camacho and Tiago L. M. Frizzo for assistance with the field and laboratory work and to Scott Powell, Jonathan Majer, and two anonymous reviewers for reading and commenting on a previous view of the manuscript. They also thank UFU for providing logistical support and the farm owners for granting access to collect in their lands. John Longino, Fernando Fernandéz, Scott Powell, Jacques Delabie, and Gordon Snelling kindly identified some of the ant species listed in this study. Financial support was provided by the Brazilian Council of Research and Scientific Development (CNPq Grants 472972/2008-1 and 143112/2008-2).

\section{References}

[1] J. T. Longino and R. K. Colwell, "Biodiversity assessment using structured inventory: capturing the ant fauna of a tropical rain forest," Ecological Applications, vol. 7, no. 4, pp. 1263-1277, 1997.

[2] K. C. Kim, "Biodiversity, conservation and inventory: why insects matter," Biodiversity and Conservation, vol. 2, no. 3, pp. 191-214, 1993.

[3] M. J. Samways, "Insects in biodiversity conservation: some perspectives and directives," Biodiversity and Conservation, vol. 2, no. 3, pp. 258-282, 1993.

[4] B. Holldobler and E. Wilson, The Ants, Belknap Press of Harvard University, Cambridge, Mass, USA, 1990.

[5] P. J. Folgarait, "Ant biodiversity and its relationship to ecosystem functioning: a review," Biodiversity and Conservation, vol. 7, no. 9, pp. 1221-1244, 1998.

[6] A. N. Andersen and J. D. Majer, "Ants show the way down under: invertebrates as bioindicators in land management," Frontiers in Ecology and the Environment, vol. 2, no. 6, pp. 291298, 2004.

[7] B. T. Bestelmeyer, D. Agosti, L. E. Alonso et al., "Field techniques for the study of ground-dwelling ants: an overview, description, and evaluation," in Ants: Standard Methods for Measuring and Monitoring Biodiversity, D. Agosti, J. D. Majer, L. E. Alonso, and T. R. Schultz, Eds., pp. 122-144, Smithsonian Institution Press, London, UK, 2000.

[8] B. L. Fisher, "Improving inventory efficiency: a case study of leaf-litter ant diversity in Madagascar," Ecological Applications, vol. 9, no. 2, pp. 714-731, 1999.

[9] H. Romero and K. Jaffe, "A comparison of methods for sampling ants (Hymenoptera, Formicidae) in Savannas," Biotropica, vol. 21, no. 4, pp. 348-352, 1989.

[10] J. H. C. Delabie, B. L. Fisher, J. D. Majer, and I. W. Wright, "Sampling effort and choice of methods", in Ants: Standard Methods for Measuring and Monitoring Biodiversity, D. Agosti, 
J. D. Majer, L. E. Alonso, and T. R. Schultz, Eds., pp. 145-154, Smithsonian Institution Press, London, UK, 2000.

[11] D. M. Olson, "A comparison of the efficacy of litter sifting and pitfall traps for sampling leaf litter ants (Hymenoptera, Formicidae) in a Tropical Wet Forest, Costa Rica," Biotropica, vol. 23, no. 2, pp. 166-172, 1991.

[12] J. T. Longino, J. Coddington, and R. K. Colwell, "The ant fauna of a tropical rain forest: estimating species richness three different ways," Ecology, vol. 83, no. 3, pp. 689-702, 2002.

[13] C. T. Lopes and H. L. Vasconcelos, "Evaluation of three methods for sampling ground-dwelling ants in the Brazilian Cerrado," Neotropical Entomology, vol. 37, no. 4, pp. 399-405, 2008.

[14] A. N. Andersen and A. Brault, "Exploring a new biodiversity frontier: subterranean ants in northern Australia," Biodiversity and Conservation, vol. 19, no. 9, pp. 2741-2750, 2010.

[15] K. T. R. Wilkie, A. L. Mertl, and J. F. A. Traniello, "Species diversity and distribution patterns of the ants of Amazonian Ecuador," PLoS ONE, vol. 5, no. 10, Article ID e13146, pp. 112, 2010.

[16] J. F. Lynch, A. K. Johnson, and E. C. Balinsky, "Spatial and temporal variation in the abundance and diversity of ants (Hymenoptera: Formicidae) in the soil and litter layers of a Maryland forest," American Midland Naturalist, vol. 119, no. 1, pp. 31-44, 1988.

[17] R. R. Silva and R. Silvestre, "Riqueza da fauna de formigas (Hymenoptera: Formicidae) que habita as camadas superficiais do solo em Seara, Santa Catarina," Papéis Avulsos de Zoologia, vol. 44, no. 1, pp. 1-11, 2004.

[18] H. L. Vasconcelos and J. H. C. Delabie, "Ground ant communities from central Amazonia forest fragments," in Sampling Ground-Dwelling Ants: Case Studies from the World's Rain Forests, D. Agosti, J. D. Majer, L. E. Alonso, and T. R. Schultz, Eds., pp. 59-70, Curtin University School of Environmental Biology, Perth, Australia, 2000.

[19] K. T. R. Wilkie, A. L. Mertl, and J. F. A. Traniello, "Biodiversity below ground: probing the subterranean ant fauna of Amazonia," Naturwissenschaften, vol. 94, no. 9, pp. 725-731, 2007.

[20] S. M. Berghoff, U. Maschwitz, and K. E. Linsenmair, "Hypogaeic and epigaeic ant diversity on Borneo: evaluation of baited sieve buckets as a study method," Tropical Zoology, vol. 16, no. 2, pp. 153-163, 2003.

[21] T. Yamaguchi and M. Hasegawa, "An experiment on ant predation in soil using a new bait trap method," Ecological Research, vol. 11, no. 1, pp. 11-16, 1996.

[22] F. A. Schmidt and R. R. C. Solar, "Hypogaeic pitfall traps: methodological advances and remarks to improve the sampling of a hidden ant fauna," Insectes Sociaux, vol. 57, no. 3, pp. 261-266, 2010.

[23] S. O’Donnell, J. Lattke, S. Powell, and M. Kaspari, "Army ants in four forests: geographic variation in raid rates and species composition," Journal of Animal Ecology, vol. 76, no. 3, pp. 580-589, 2007.

[24] C. A. Klink and R. B. Machado, "Conservation of the Brazilian Cerrado," Conservation Biology, vol. 19, no. 3, pp. 707-713, 2005.

[25] A. T. Oliveira-Filho and J. A. Ratter, "Vegetation physiognomies and woody flora of the Cerrado biome," in The Cerrados of Brazil: Ecology and Natural History of a Neotropical Savanna, P. S. Oliveira and R. J. Marquis, Eds., pp. 91-120, Columbia University Press, New York, NY, USA, 2002.

[26] C. T. Parr and S. L. Chown, "Inventory and bioindicator sampling: testing pitfall and winkler methods with ants in a South
African Savanna," Journal of Insect Conservation, vol. 5, no. 1, pp. 27-36, 2001.

[27] S. M. Berghoff, A. Weissflog, K. E. Linsenmair, R. Hashim, and U. Maschwitz, "Foraging of a hypogaeic army ant: a long neglected majority," Insectes Sociaux, vol. 49, no. 2, pp. 133$141,2002$.

[28] A. Weissflog, E. Sternheim, W. H. O. Dorow, S. Berghoff, and U. Maschwitz, "How to study subterranean army ants: a novel method for locating and monitoring field populations of the South East Asian army ant Dorylus (Dichthadia) laevigatus Smith, 1857 (Formicidae, Dorylinae) with observations on their ecology," Insectes Sociaux, vol. 47, no. 4, pp. 317-324, 2000.

[29] N. J. Gotelli and R. K. Colwell, "Quantifying biodiversity: procedures and pitfalls in the measurement and comparison of species richness," Ecology Letters, vol. 4, no. 4, pp. 379-391, 2001.

[30] R. K. Colwell, "EstimateS: Statistical estimation of species richness and shared species from samples," 2009, http://viceroy .eeb.uconn.edu/estimates.

[31] J. H. Delabie and H. G. Fowler, "Soil and litter cryptic ant assemblages of Bahian cocoa plantations," Pedobiologia, vol. 39, no. 5, pp. 423-433, 1995.

[32] C. R. F. Brandão, R. M. Feitosa, F. A. Schmidt, and R. R. D. C. Solar, "Rediscovery of the putatively extinct ant species Simopelta minima (Brandão) (Hymenoptera, Formicidae), with a discussion on rarity and conservation status of ant species," Revista Brasileira de Entomologia, vol. 52, no. 3, pp. 480-483, 2008.

[33] C. R. F. Brandão, M. Verhaag, and J. L. M. Diniz, "A new ant subfamily from central Amazon soil samples," in Proceedings of the 14th International Congress of IUSSI, Hokkaido University, Sapporo, Japan, 2002. 

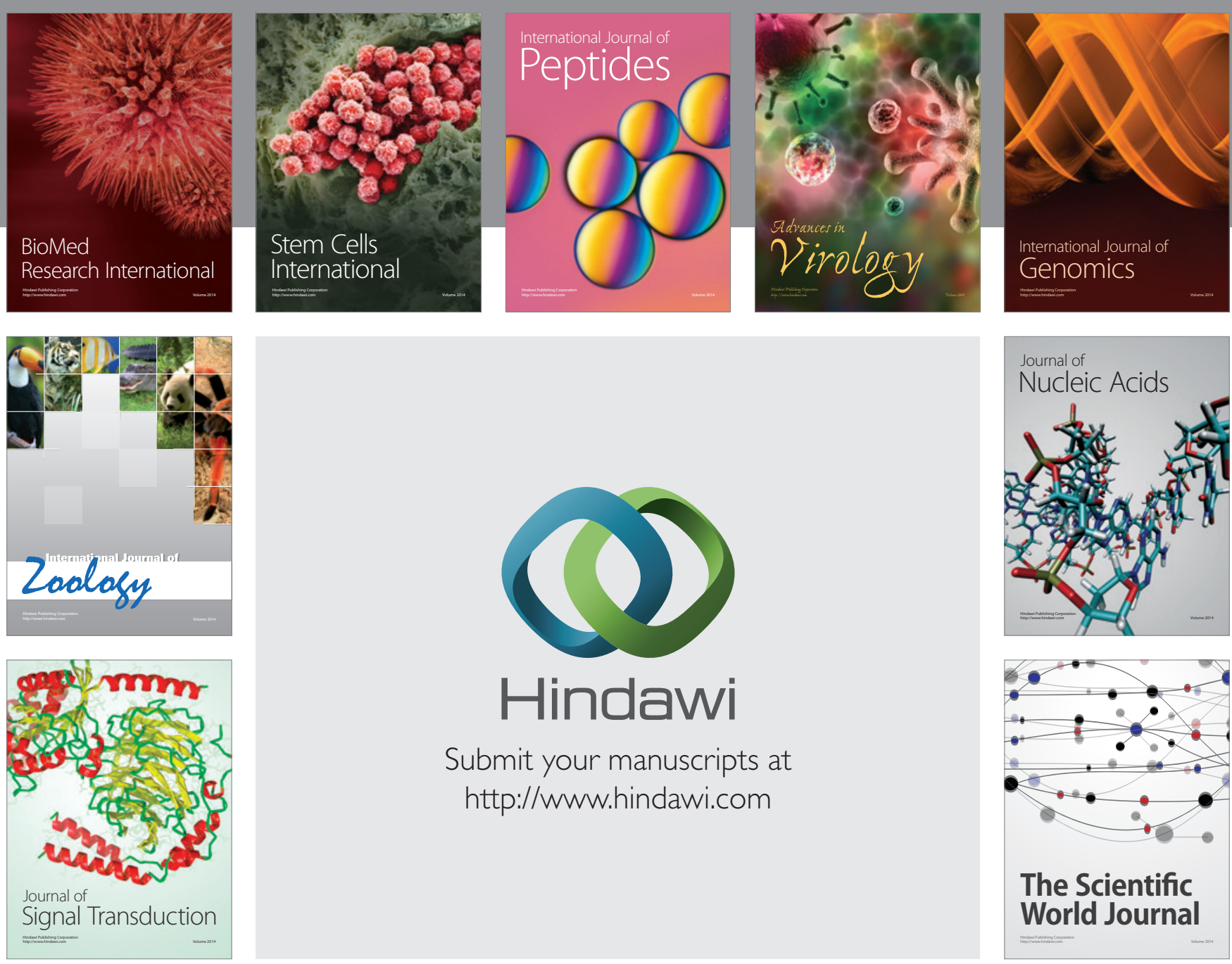

Submit your manuscripts at

http://www.hindawi.com
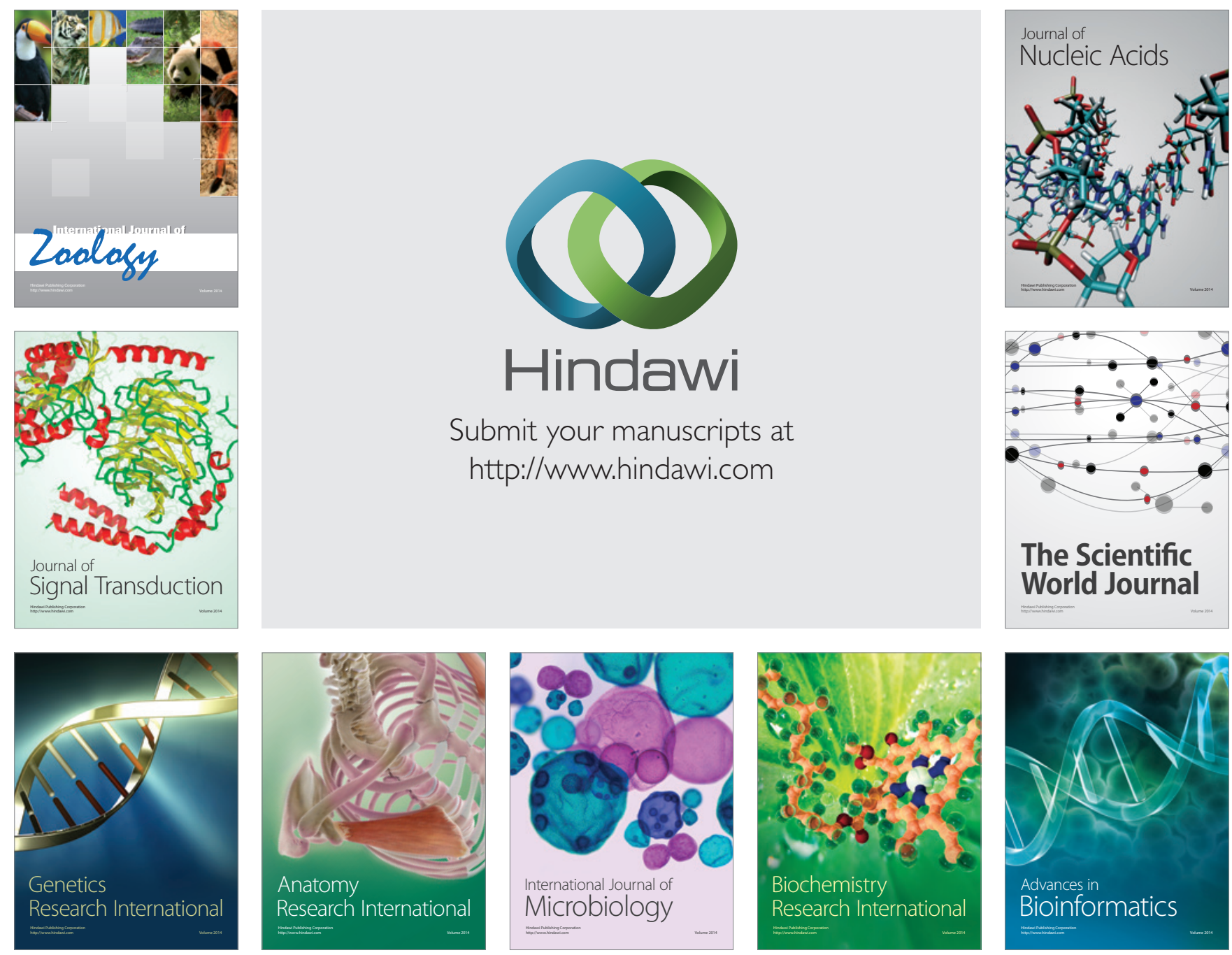

The Scientific World Journal
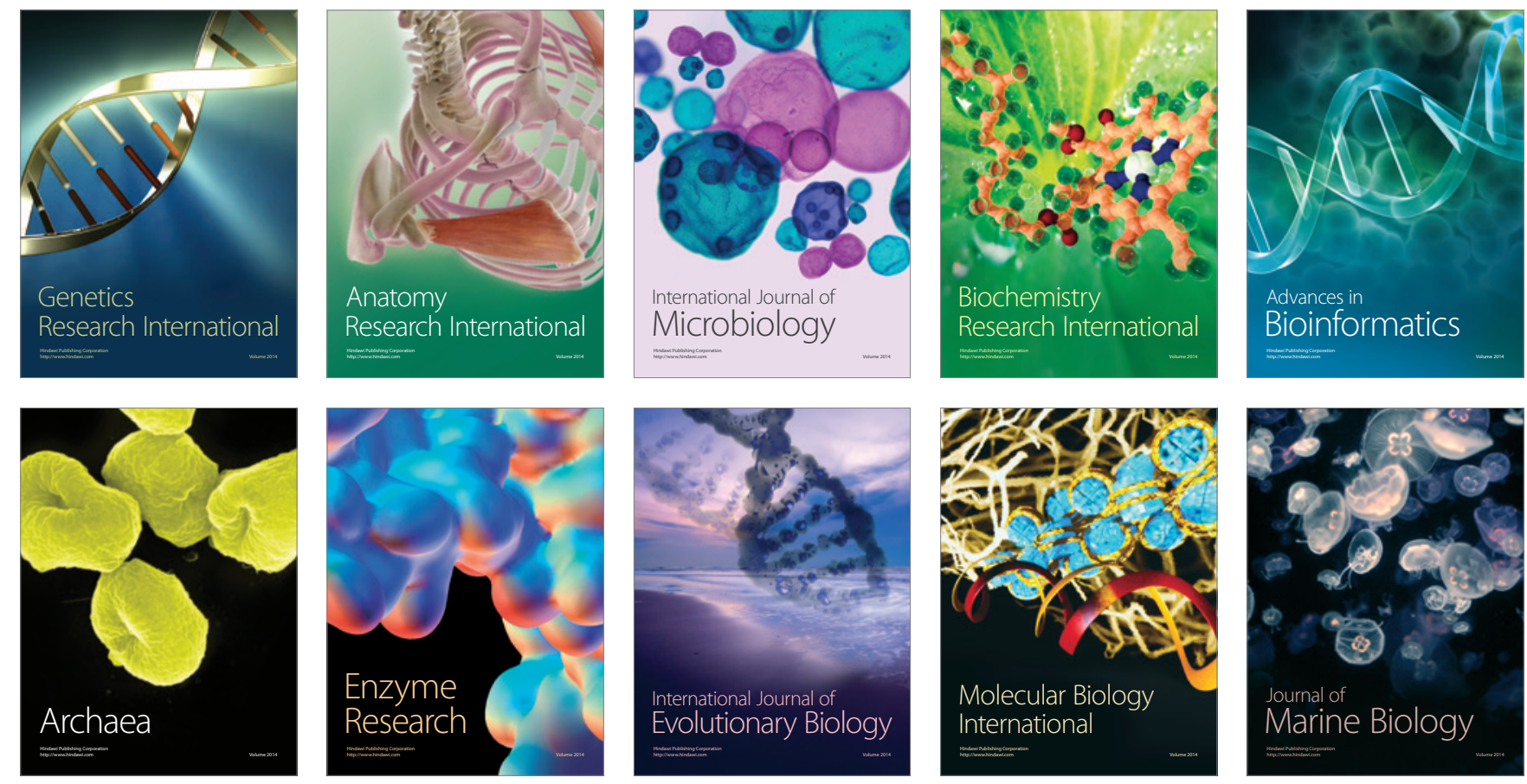